\title{
Drug-related problems and their clinical interventions in a Ghanaian teaching hospital
}

\author{
Franklin Acheampong ${ }^{1 *} \mathbb{D}$, Florence Amah Nkansah $^{2}$ and Berko Panyin Anto ${ }^{3}$
}

\begin{abstract}
Background: Errors occur frequently in the use of medicines. Pharmacists play a key role in error identification and make appropriate interventions as they work with other healthcare professionals. These error recovery roles of pharmacists contribute to patient safety. This study was to evaluate the clinical interventions made to drug-related problems at a tertiary care setting.

Method: This involved a retrospective review of clinical intervention reports submitted by pharmacists working over the period January 2011 to December 2013.

Results: The 24 pharmacists submitted 529 handwritten reports; of these, 448 reports had complete data. The most frequently reported drugs with error were warfarin (9.5\%), potassium chloride (6.0\%) and potassium citrate (5.5\%). The pharmacists made 1019 clinical interventions and recommendations. The average intervention per report was 2.5 (S.D \pm 0.67$)$. The interventions and recommendations made were categorised as drug regimen change (76.1\%), monitoring required (13.0\%), communication (5.4\%), counselling required (5.0\%) and adverse drug reporting (0.6\%). Majority (90.5\%) of the recommendations and interventions made by pharmacists were accepted and implemented. Monitoring-required based interventions were significantly more likely to be accepted (130 vs 38; $p<0.0001$ ).
\end{abstract}

Conclusion: Pharmacists played a role in drug error recovery and prevented medication errors from reaching patients. These error mitigation efforts of pharmacists can serve as a priority in patient safety strategy.

Keywords: Medication errors, Patient safety, Pharmacist, Clinical interventions, Ghana

\section{Background}

A substantial proportion of hospitalised patients experience medication-related harm that is preventable [1]. Drug errors have been estimated to account for over a quarter of causes of adverse drug events [2]. Strategies to prevent such problems are being developed. One such strategy is the structured review of patient medication by pharmacists to identify patients with medication errors that may lead to harm. The advantage is that the complete clinical status of each patient is taken into account when identifying problems [3]. In a study, clinical pharmacists performed better than the decision support system in identifying drug-drug interactions clinical interventions [4]. The authors realised that clinical

\footnotetext{
* Correspondence: franklinach@hotmail.co.uk

${ }^{1}$ Korle Bu Teaching Hospital, P.O. Box 77, Accra, Ghana

Full list of author information is available at the end of the article
}

pharmacists looked at individual administration intervals and drug sequence to determine the clinical relevance of the interactions.

The Harvard Medical Practice Study analysed error recovery, i.e. the circumstances under which errors were detected and corrected. The study acknowledged the important role pharmacists play in identifying and correcting drug errors from reaching patients.

The Institute of Medicine's report includes recommendations for health systems to implement error reporting reviews [5]. In the inpatient setting, clinicians have used various drug event reporting programs to better understand and prevent drug errors $[6,7]$. The interception of medication errors is thus essential for improving patient safety. The aim of the study was therefore to evaluate the clinical interventions of hospital pharmacists. 


\section{Methods}

The study was a retrospective review of reports, which had no names, nor personal information of patients. No consent was taken from patients since they could not be traced to any reports.

\section{Study setting}

The study took place at Korle $\mathrm{Bu}$ Teaching hospital which is a 2000 bed tertiary teaching hospital located in the capital city of Ghana. At the time of the study, the hospital had about 80 pharmacists. The main pharmacy services provided in the hospital were dispensing, clinical, drug information, research and small scale manufacturing. There were about 30 pharmacists who actively undertake clinical duties across the various wards of the hospital.

\section{Data collection}

To evaluate the clinical interventions of pharmacists working in the hospital, copies of reports for the period January 2011-December 2013 were made and relevant data extracted using a specially designed data collection sheet. Pharmacists had previously identified drug errors and manually reported the clinical interventions. The pharmacist interventions accepted and the actions taken were reported on the submitted manual reports. Pharmacists had discovered drug errors during their normal duties from review of patient medical records, laboratory reports, interactions with other health care professionals, patients, caregivers or family members.

\section{Data analysis}

The extracted clinical intervention data was entered into and analysed using SPSS (Statistical Package for Social Sciences) version 16 for Windows. Descriptive analysis was performed on all the data to obtain the frequency of clinical interventions, drug characteristics and pharmacist characteristics. Aggregate data were tabulated and summarized using frequency statistics such as count, range, mean and standard deviation. Descriptive analyses of all drug error types and related interventions were also tabulated. Pharmacist Clinical intervention data were compared between drug classifications, drug error types and whether pharmacist interventions were accepted or not using Chi square test dichotomous variables. Any $p<0.05$ was considered as statistically significant.

\section{Results}

\section{Study participants}

The evaluation revealed that 24 pharmacists made 529 paper-based reports over the 3 years. Majority of them were female (70.8\%) and more than half had less than 10 years experience (53.3\%). The basic characteristics of pharmacists who made the reports are presented in Table 1.
Table 1 Characteristics of pharmacists involved in reporting $(N=24)$

\begin{tabular}{lll}
\hline Characteristic & Number & Percent \\
\hline Sex & 7 & \\
Male & 17 & 29.2 \\
$\quad$ Female & & 70.8 \\
Experience in practice (years) & 6 & 25.00 \\
$0-5$ & 8 & 33.33 \\
$>5-10$ & 3 & 12.50 \\
$>10-15$ & 5 & 20.83 \\
$>15-20$ & 2 & 8.33 \\
$>20$ & & \\
Education \& training & 8 & 33.3 \\
MSc in clinical pharmacy & 3 & 12.5 \\
MSc Clinical Pharmacy (student) & 13 & 54.2 \\
BPharm
\end{tabular}

\section{Drug error reports}

Of the 529 paper-based drug error reports, 448 contained complete information and hence were included in the study. Reasons for not including the 79 were no drug name $(n=67)$, no reason for error $(n=6)$ and no recommendation $(n=6)$. Drug errors were reported from all the units of the hospital that pharmacists worked; surgery $(24 \%)$, medicine $(22 \%)$, paediatric $(21 \%)$, obstetrics and gynaecology (17\%) and others (16\%). Pharmacists discovered drug errors from review of patient medical records (74\%), from other health care professionals (10\%), laboratory reports $(8 \%)$, patients $(6 \%)$, caregivers (1\%), and other unspecified sources (3\%). The frequently occurring therapeutic drug categories with errors were cardiovascular (44.4\%), infections (22.8\%), nutrition (12.9\%) and musculoskeletal (6.6\%). Table 2 describes the therapeutic drug categories and the degree of acceptance. The five most frequently reported classes of drugs associated with drug errors were antibiotics (20.2\%), anticoagulants (19.9), iron supplement (16.3\%), diuretics (9.4\%) and non-steroidal anti-inflammatory drugs (4.4\%). The most frequently reported drugs with error were warfarin $(9.5 \%)$, potassium chloride $(6.0 \%)$ and potassium citrate $(5.5 \%)$. The drug error types identified were categorised as prescribing, dispensing/implementing, administering/patient receiving and monitoring (see Table 3). Majority of reported drug errors were due to prescribing (70.9\%) and least due to dispensing/implementing $(2.0 \%)$. The most frequently reported drugs associated with prescribing errors included cardiovascular (42.6\%), anti-infectives (22.9), and nutritional agents (10.5\%). During dispensing or implementation, the frequently reported drug errors were anti-infectives (50.0\%), endocrine (35.0\%) and cardiovascular (15.0\%). 
Table 2 Therapeutic category of drugs with intervention reports

\begin{tabular}{|c|c|c|c|c|}
\hline \multirow[t]{2}{*}{ Drug category } & \multirow[t]{2}{*}{ Indication } & \multicolumn{2}{|c|}{ Number of recommended interventions } & \multirow[t]{2}{*}{${ }^{*} p$-value } \\
\hline & & Accepted & Not accepted & \\
\hline \multirow[t]{10}{*}{ Cardiovascular ( $n=451[44.3 \%])$} & Anticoagulant & 181 & 22 & 0.053 \\
\hline & Diuretic & 87 & 9 & $<0.001$ \\
\hline & Calcium channel blockers & 16 & 8 & $<0.001$ \\
\hline & Beta blockers & 20 & 2 & 0.037 \\
\hline & ACE inhibitors & 14 & 2 & 0.003 \\
\hline & Statin & 17 & 3 & $<0.001$ \\
\hline & Antiplatelet & 15 & 1 & 0.001 \\
\hline & Nitrates & 4 & 0 & 0.061 \\
\hline & Angiotensin receptor blockers & 3 & 0 & $<0.001$ \\
\hline & Others & 41 & 6 & 0.004 \\
\hline \multirow[t]{4}{*}{ Infections ( $n=231[22.7 \%])$} & Antibiotics & 180 & 18 & 0.019 \\
\hline & Antimalarials & 26 & 0 & 0.009 \\
\hline & Antivirals & 5 & 0 & 0.101 \\
\hline & Antifungal & 2 & 0 & 0.023 \\
\hline \multirow[t]{2}{*}{ Nutrition (129 [12.7\%]) } & Iron supplement & 106 & 13 & 0.037 \\
\hline & Others & 10 & 0 & $<0.001$ \\
\hline \multirow[t]{3}{*}{ Musculoskeletal (70 [6.9\%]) } & NSAIDS & 52 & 3 & 0.010 \\
\hline & Systemic Corticosteroids & 11 & 0 & $<0.001$ \\
\hline & Others & 4 & 0 & $<0.001$ \\
\hline \multirow[t]{3}{*}{ Central Nervous System (51[5\%]) } & Opiod analgesic & 39 & 3 & $<0.001$ \\
\hline & Sedatives & 6 & 0 & $<0.001$ \\
\hline & Antiepileptic & 2 & 1 & 0.122 \\
\hline \multirow[t]{4}{*}{ Gastro-Intestinal (50 [4.9\%]) } & Proton pump inhibitor & 27 & 3 & 0.027 \\
\hline & Antacid & 7 & 0 & 0.980 \\
\hline & Laxative & 5 & 0 & 0.001 \\
\hline & Others & 6 & 2 & 0.001 \\
\hline \multirow[t]{2}{*}{ Endocrine (14 [1.4\%]) } & Oral antidiabetics & 9 & 1 & 0.076 \\
\hline & Insulin & 4 & 0 & 0.001 \\
\hline \multirow[t]{2}{*}{ Respiratory (11 [1.1\%]) } & Inhalational steroids & 10 & 0 & 0.530 \\
\hline & Antihistamine & 1 & 0 & 0.890 \\
\hline Others (12 [1.2\%]) & & 12 & 0 & $<0.001$ \\
\hline
\end{tabular}

${ }^{*}$ Cross tabulation $\left(x^{2}\right.$ test) between accepted and not accepted interventions for each Indication and the rest

The most frequently reported drug category associated with administration or patient receiving included antiinfectives (45.5\%), cardiovascular (22.7\%) and central nervous system (15.2\%). The common reasons pharmacists provided for drug errors included untreated indication (18.9\%), wrong dose prescribed (12.5\%), wrong drug prescribed (11.4\%), medicine interactions $(10.7 \%)$ and duplication of therapy $(9.8 \%)$.

\section{Clinical interventions}

The twenty most frequently drugs occurring in intervention reports and their potential risk are presented in Table 4. The pharmacists made 1019 interventions and recommendations in 448 handwritten reports. The average intervention per report was 2.5 , standard deviation $( \pm 0.67)$, range (2-4), and mode (2). The interventions and recommendations made have been categorised as drug regimen change $(76.1 \%)$, monitoring required $(13.0 \%)$, communication $(5.4 \%)$, counselling required $(5.0 \%)$ and adverse drug reporting $(0.6 \%)$. The intervention types have been summarised in Table 5. Monitoring-required based interventions were significantly more likely to be accepted (130 vs $38 ; p<0.0001)$. Drugs involving drug regimen adjustment by pharmacists included potassium citrate $(n=$ $56)$, enoxaparin $(n=54)$, warfarin $(n=42)$, diclofenac 
Table 3 Drug error types and reasons

\begin{tabular}{|c|c|c|}
\hline Error type & Reasons & Number \\
\hline \multirow[t]{10}{*}{ Prescribing $(n=721)$} & Untreated indications & 174 \\
\hline & Wrong dose prescribed & 127 \\
\hline & Wrong drug prescribed & 116 \\
\hline & Medicine interactions & 93 \\
\hline & Duplication of therapy & 84 \\
\hline & Contraindications & 78 \\
\hline & Side effects & 50 \\
\hline & Failure to stop order & 44 \\
\hline & Omitted lab test & 18 \\
\hline & Others & 15 \\
\hline \multirow{3}{*}{$\begin{array}{l}\text { Dispensing/implementing } \\
(n=20)\end{array}$} & Wrong drug dispensed & 14 \\
\hline & Wrong label & 5 \\
\hline & Others & 1 \\
\hline \multirow{7}{*}{$\begin{array}{l}\text { Administering/patient } \\
\text { receiving }(n=66)\end{array}$} & Unavailability of drug & 19 \\
\hline & Wrong dose administered & 16 \\
\hline & Duplication & 16 \\
\hline & Failure to discontinue & 7 \\
\hline & Others & 4 \\
\hline & Wrong drug administered & 3 \\
\hline & Wrong dosage form & 1 \\
\hline \multirow[t]{7}{*}{ Monitoring $(n=212)$} & Laboratory test omitted & 91 \\
\hline & Blood glucose not monitored & 77 \\
\hline & Side effects not monitored & 40 \\
\hline & Others & 19 \\
\hline & $\begin{array}{l}\text { Medicine-disease interactions not } \\
\text { monitored }\end{array}$ & 16 \\
\hline & Culture and sensitivity omitted & 14 \\
\hline & BP not checked & 11 \\
\hline
\end{tabular}

$(n=40)$, and morphine $(n=37)$. Monitoring required interventions were made for potassium chloride $(n=46)$, frusemide $(n=22)$, warfarin $(n=20)$, gentamicin $(n=19)$ and metolazone $(n=14)$. Drugs requiring counselling included warfarin $(n=44)$, iron supplement $(n=12)$, inhaled steroid $(n=6)$, insulin $(n=4)$, and lamivudine $(n=3)$. Drugs involving communication between pharmacist and other healthcare professionals included frusemide $(n=31)$, diclofenac $(n=18)$, iron supplement $(n=16)$, warfarin $(n=11)$ and antacid $(n=7)$. Majority $(90.5 \%)$ of the recommendations and interventions made by pharmacists were accepted by prescribers and other healthcare professionals (see Table 5). These interventions were communicated via the following means: verbal (76.4\%), write in patient medical notes $(16.3 \%)$, acted upon by reporting pharmacist (6.1\%), prepare formal note $(0.7 \%)$ and prescribe/procure for patient $(0.5 \%)$.

\section{Discussion}

This part of the study evaluated the clinical intervention reports submitted by pharmacists working in a tertiary hospital. The pharmacists identified drug related problems in the management of patients and made interventions to prevent these errors from reaching patients. Twenty-four pharmacists made 1019 clinical interventions in 448 handwritten reports. Majority of the interventions related to drug therapy changes. Though this study evaluated handwritten reports, it is comparable to evaluations done on electronic incident reports $[8,9]$.

The categories of drugs most often associated with drug error reports were similar to those reported from previous studies and included cardiovascular agents $[10,11]$, anti-infectives $[11,12]$, and central nervous system agents $[10,13]$, suggesting that future strategies for reducing drug errors could target these agents. This study also found challenges with the use of nutritional supplements. Most of the challenges with nutritional supplements had to do with untreated anaemia, which physicians had overlooked. Iron deficiency anaemia is a serious nutritional problem in developing countries given its impact on increased mortality or serious morbidity in patients [14].

The frequently reported drug was warfarin as found in other studies [15]. The use of warfarin presents substantial safety concerns for patients. Adverse events associated with warfarin therapy are common [16]. This will require prevention strategies targeted at the prescribing and monitoring stages of warfarin management.

Though this study concentrated on pharmacists identifying inpatient drug errors as in other studies, results are comparable with studies conducted in outpatients [11, 17-20]. The drug errors assessed in this study were reports from only pharmacists although physicians [11, 21], nurses [22, 23] and others [24, 25] had reported drug errors in other studies.

The most frequently reported drug errors found in our study were drug regimen change and originated from drug prescribing. This finding is consistent with findings from other studies conducted in clinical centres [26], tertiary [27], hospital inpatient [28] and ambulatory care settings [11]. Inappropriate prescribing predicts the risk of adverse drug events [29]. The most commonly reported prescribing drug error was untreated indication. This was followed by prescribing wrong dose as seen in other studies [11, 30]. Children are particularly at risk of wrong dose errors [31].

The top two most frequently reported drug type associated with prescribing, dispensing and administration errors were cardiovascular and anti-infective agents. The most commonly reported dispensing error was dispensing wrong drug. Previous studies have reported dispensing wrong drugs in all types of 
Table 4 Drugs most frequently occurring in intervention reports and their potential risk

\begin{tabular}{|c|c|c|c|c|}
\hline \multirow[t]{2}{*}{ Drug } & \multirow{2}{*}{$\begin{array}{l}\text { Number in reports, } \\
\mathrm{n}(\%)\end{array}$} & \multirow{2}{*}{$\begin{array}{l}\text { Examples of potential } \\
\text { risk }\end{array}$} & \multicolumn{2}{|c|}{ Outcome of intervention } \\
\hline & & & Accepted & Not accepted \\
\hline Warfarin & $97(9.5)$ & Bleeding & 89 & 8 \\
\hline Slow K & $61(6.0)$ & Electrolyte imbalance & 56 & 5 \\
\hline Gentamicin & $60(5.9)$ & Tinnitus & 45 & 15 \\
\hline Potassium Citrate & $56(5.5)$ & Electrolyte imbalance & 41 & 15 \\
\hline Enoxaparin & $55(5.4)$ & DVT & 46 & 9 \\
\hline Diclofenac & $43(4.2)$ & Gastrointestinal bleeding & 40 & 3 \\
\hline Heparin & $39(3.8)$ & Bleeding & 34 & 5 \\
\hline Morphine & $38(3.7)$ & Respiratory depression & 35 & 3 \\
\hline Frusemide & $37(3.6)$ & Electrolyte imbalance & 29 & 8 \\
\hline Iron Supplement & $37(3.6)$ & Anaemia & 34 & 3 \\
\hline Clindamycin & $27(2.6)$ & Diarrhoea & 25 & 2 \\
\hline Metolazone & $26(2.6)$ & Electrolyte imbalance & 26 & 0 \\
\hline Omeprazole & $24(2.4)$ & Gastrointestinal bleeding & 21 & 3 \\
\hline Atenolol & $20(2)$ & Heart block & 19 & 1 \\
\hline Hydrochlorthiazide & $18(1.8)$ & Electrolyte imbalance & 18 & 0 \\
\hline Metronidazole & $16(1.6)$ & Increased hospital cost & 14 & 2 \\
\hline Rosuvastatin & $15(1.5)$ & Cardiovascular event & 15 & 0 \\
\hline Cefuroxime & $13(1.3)$ & Severe diarrhoea & 13 & 0 \\
\hline Ciprofloxacin & $13(1.3)$ & Muscle weakness & 13 & 0 \\
\hline Lisinopril & $13(1.3)$ & Neonatal mortality & 11 & 2 \\
\hline
\end{tabular}

inpatient settings $[25,32-35]$. Omission due to drug unavailability was also a common error identified. Drug unavailability is common and poses a major challenge to healthcare systems in transitional and developing countries [36, 37]. In addition to drug omissions, administering wrong drug followed by duplication were common reported administration errors. The most commonly reported monitoring error was omitting relevant laboratory test. Monitoring errors had been previously reported [11].

Table 5 Types of pharmacist clinical interventions and degree of acceptance

\begin{tabular}{|c|c|c|c|c|}
\hline \multirow[t]{2}{*}{ Intervention type } & \multirow[t]{2}{*}{ Method } & \multirow[t]{2}{*}{ Number of reports } & \multicolumn{2}{|c|}{ Acceptance } \\
\hline & & & Yes, n (\%) & No, n (\%) \\
\hline \multirow[t]{4}{*}{ Drug regimen change $(n=775[76.1 \%])$} & Verbal & 643 & $730(94)$ & $45(6)$ \\
\hline & Write in medical notes & 109 & & \\
\hline & Acted on by pharmacist & 20 & & \\
\hline & Prescribe/procure for patient & 3 & & \\
\hline \multirow[t]{3}{*}{ Monitoring required $(n=132$ [13\%]) } & Verbal & 82 & $130(98)$ & $2(2)$ \\
\hline & Write in patient medical notes & 49 & & \\
\hline & Write formal note & 1 & & \\
\hline \multirow[t]{3}{*}{ Counselling required $(n=52[5.1 \%])$} & Verbal & 9 & $49(94)$ & $3(6)$ \\
\hline & Acted on by pharmacist & 42 & & \\
\hline & Prescribe/procure for patient & 1 & & \\
\hline \multirow[t]{3}{*}{ Communication $(n=54[5.3 \%])$} & Verbal & 45 & $50(93)$ & $4(7)$ \\
\hline & Write in medical notes & 8 & & \\
\hline & Prescribe/procure for patient & 1 & & \\
\hline Adverse drug reporting $(n=6[0.6 \%])$ & Write formal note & 6 & $6(100)$ & $0(0)$ \\
\hline
\end{tabular}


More than $90 \%$ of interventions and recommendations by pharmacists were accepted and implemented. Over $70 \%$ of the interventions involved drug regimen change. Studies have reported prescribing errors as a major contributor to patient harm in hospitals [10, 26, 28, 29, 38]. Most (76\%) of the interventions were communicated verbally. This would require an operational collaborative working relationship between pharmacists and other healthcare professionals to enhance patient care [39]. Previous studies reported that pharmacists in a collaborative team in hospitals helped reduce adverse drug events by $30-86 \%[19,40-42]$. Pharmacists' close proximity with physicians provides opportunity for timely verbal communications on error interceptions. Some of the potential risk prevented by pharmacists included bleeding, anaemia, nephrotoxicity, electrolyte imbalance, severe diarrhoea etc.

Moreover, other interventions by pharmacists in this study related to patient counselling. It has been reported that patient counselling prevents adverse drug events during and after hospitalisation [43].

The study had some limitations. The study evaluated voluntary incident reports. Voluntary reports could be underreported and did not provide the actual frequency of the total denominator of errors that were detected and ameliorated. Secondly, reports did not contain information on whether errors reached patients and the effects of any harm. Moreover, the study could not assess the outcomes of the interventions performed by pharmacist.

\section{Conclusions}

Hospital pharmacists identified a lot of drug use challenges and subsequently prevented errors from reaching patients. Majority of pharmacist interventions and recommendations to prevent or ameliorate drug errors were accepted and implemented.

\section{Acknowledgements}

Not applicable.

\section{Funding}

The study did not receive any external funding.

\section{Availability of data and materials}

Please contact author for data requests.

\section{Authors' contributions}

FA was involved in conceptualization, research design, data collection, data analysis, statistical analysis and drafting of manuscripts. FAN was involved in data analysis and reviewing and editing of manuscripts. BPA was involved in study conceptualization, and editing of final manuscript. All authors read, reviewed and edited the final manuscript and approved the final manuscript in its current state.

\section{Competing interests}

The authors declare that they have no competing interests.
Consent for publication

Not applicable.

\section{Ethics approval and consent to participate}

The work was reviewed by the Internal Review Board of the Public Health Unit of Korle Bu Teaching Hospital and the Ethical and

Protocol Review Committee of the University of Ghana Medical School (MS-Et/M.3-P3.1/2013-2014).

\section{Informed consent}

It was a retrospective review and did not require informed consent. However, codes were used to refer to patients such that the identity of participants were not known.

\section{Author details}

'Korle Bu Teaching Hospital, P.O. Box 77, Accra, Ghana. ${ }^{2}$ Pharmacy Department, Korle Bu Teaching Hospital, P.O. Box 77, Accra, Ghana. ${ }^{3}$ Department of Clinical and Social Pharmacy, Kwame Nkrumah University of Science and Technology, Kumasi, Ghana.

Received: 24 October 2016 Accepted: 10 November 2016

Published online: 30 November 2016

References

1. Brennan TA, et al. Incidence of adverse events and negligence in hospitalized patients. Results of the Harvard Medical Practice Study I. N Engl J Med. 1991;324(6):370-6.

2. Bates DW, et al. Relationship between medication errors and adverse drug events. J Gen Intern Med. 1995;10(4):199-205.

3. van Doormaal JE, et al. Comparison of methods for identifying patients at risk of medication-related harm. Qual Saf Health Care. 2010;19:26.

4. Cornu P, et al. Performance of a clinical decision support system and of clinical pharmacists in preventing drug-drug interactions on a geriatric ward. Int J Clin Pharm. 2014;36(3):519.

5. Kohn LT, Corrigan J, Donaldson MS. Committee on Quality of Health Care in America, Institute of Medicine. To Err is Human: Building a Safer Health System. Washington DC: National Academy Press; 2000.

6. Aspden $P$, et al. Preventing medication errors: quality chasm series. Washington DC: National Academies Press; 2006.

7. Bates DW, et al. The impact of computerized physician order entry on medication error prevention. JAMIA. 1999;6:313-21.

8. Budnitz DS, et al. National surveillance of emergency department visits for outpatient adverse drug events. JAMA. 2006;296(15):1858-66.

9. Tariq A, Georgiou A, Westbrook J. Medication incident reporting in residential aged care facilities: limitations and risks to residents' safety. BMC Geriatr. 2012;12:67.

10. Lesar TS, Lomaestro BM, Pohl H. Medication-prescribing errors in a teaching hospital: a 9-year experience. Arch Intern Med. 1997:157(14):1569.

11. Kuo GM, et al. Medication errors reported by US family physicians and their office staff. Qual Saf Health Care. 2008;17(4):286-90.

12. Silva DC, et al. Adverse drug events in a paediatric intensive care unit: a prospective cohort. BMJ Open. 2013;3:e001868. doi:10.1136/bmjopen-2012001868

13. Hansen RA, et al. Types of medication errors in North Carolina nursing homes: a target for quality improvement. Am J Geriatr Pharmacother. 2006; 4(1):52-61.

14. DeMaeyer EM. Preventing and controlling iron defiency anaemia through primary health care: a guide for health administrators and programme managers. Geneva: World Health Organization; 1989.

15. Gurwitz JH, et al. The safety of warfarin therapy in the nursing home setting. Am J Med. 2007;120(6):539-44.

16. Zhan C, et al. How useful are voluntary medication error reports? The case of warfarin-related medication errors. Jt Comm J Qual Patient Saf. 2008; 34(1):36-45.

17. Aljadhey $\mathrm{H}$, et al. Medication safety practices in hospitals: a national survey in Saudi Arabia. Saudi Pharm J. 2013:21(2):159-64.

18. Bourgeois FT, et al. Pediatric adverse drug events in the outpatient setting: an 11-year national analysis. Pediatrics. 2009:124(4):e744-50.

19. Murray MD, et al. Effect of a pharmacist on adverse drug events and medication errors in outpatients with cardiovascular disease. Arch Intern Med. 2009;169(8):757-63. 
20. Sarkar U, et al. Adverse drug events in U.S. adult ambulatory medical care. Health Serv Res. 2011;46(5):1517-33.

21. Scott HD, et al. Physician reporting of adverse drug reactions: results of the Rhode Island adverse drug reaction reporting project. JAMA. 1990;263(13): 1785-8.

22. Bates DW, et al. Incidence of adverse drug events and potential adverse drug events. Implications for prevention. ADE Prevention Study Group. JAMA. 1995;274(1):29-34

23. Pagnamenta $A$, et al. Adverse event reporting in adult intensive care units and the impact of a multifaceted intervention on drug-related adverse events. Ann Intensive Care. 2012;2(1):47.

24. Hartwig SC, Denger SD, Schneider PJ. Severity-indexed, incident reportbased medication error-reporting program. Am J Health Syst Pharm. 1991; 48(12):2611-6.

25. Costa LA, Valli C, Alvarenga AP. Medication dispensing errors at a public pediatric hospital. Rev Lat Am Enfermagem. 2008;16(5):812-7.

26. Franklin $\mathrm{BD}$, et al. Prescribing errors in hospital inpatients: a three-centre study of their prevalence, types and causes. Postgrad Med J. 2011;87(1033): 739-45.

27. Al-Jeraisy Ml, Alanazi MQ, Abolfotouh MA. Medication prescribing errors in a pediatric inpatient tertiary care setting in Saudi Arabia. BMC Res Notes. 2011:4(1):294.

28. Dean $B$, et al. Prescribing errors in hospital inpatients: their incidence and clinical significance. Qual Saf Health Care. 2002;11(4):340-4.

29. Lund $B C$, et al. Inappropriate prescribing predicts adverse drug events in older adults. Ann Pharmacother. 2010;44(6):957-63.

30. Raju TK, et al. Medication errors in neonatal and paediatric intensive-care units. Lancet. 1989;334(8659):374-6.

31. Fernandez-Llamazares CM, et al. Profile of prescribing errors detected by clinical pharmacists in paediatric hospitals in Spain. Int I Clin Pharm. 2013; 35(4):638-46.

32. Rolland P. Occurrence of dispensing errors and efforts to reduce medication errors at the Central Arkansas Veteran's Healthcare System. Drug Saf. 2004; 27(4):271-82.

33. Roberts DE, et al. An analysis of dispensing errors in NHS hospitals. Int $J$ Pharm Pract. 2002;10(S1):R6.

34. Facchinetti NJ, Campbell GM, Jones DP. Evaluating dispensing error detection rates in a hospital pharmacy. Med Care. 1999;37(1):39-43.

35. Bohand X, et al. Frequency, types, and potential clinical significance of medication-dispensing errors. Clinics. 2009;64(1):11-6.

36. Agalu $A$, et al. Medication administration errors in an intensive care unit in Ethiopia. Int Arch Med. 2012;5(1):15.

37. Nunes CFP, et al. A survey of medication error prevalence in a Brazilian Health Center. J Nurs Care Qual. 2013;28(1):92-7.

38. Lewis PJ, et al. Prevalence, incidence and nature of prescribing errors in hospital inpatients: a systematic review. Drug Saf. 2009;32(5):379-89.

39. McDonough PR, Doucette WR. Developing colloborative working relationship between pharmacists and physicians. J Am Pharm Assoc. 2001; 41(5):682-92.

40. Patanwala $A E$, et al. A prospective, multicenter study of pharmacist activities resulting in medication error interception in the emergency department. Ann Emerg Med. 2012;59(5):369-73.

41. Leape LL, et al. Pharmacist participation on physician rounds and adverse drug events in the intensive care unit. JAMA. 1999;282(3):267-70.

42. Klopotowska JE, et al. On-ward participation of a hospital pharmacist in a Dutch intensive care unit reduces prescribing errors and related patient harm: an intervention study. Crit Care. 2011;14:174-85.

43. Schnipper $\mathrm{J}$, et al. Role of pharmacist counseling in preventing adverse drug events after hospitalization. Arch Intern Med. 2006;166(5):565-71.

\section{Submit your next manuscript to BioMed Central and we will help you at every step:}

- We accept pre-submission inquiries

- Our selector tool helps you to find the most relevant journal

- We provide round the clock customer support

- Convenient online submission

- Thorough peer review

- Inclusion in PubMed and all major indexing services

- Maximum visibility for your research

Submit your manuscript at www.biomedcentral.com/submit

) Biomed Central 